\title{
TECNOLOGIA DA INFORMAÇÃO COMO APOIO À PARTICIPAÇÃO SOCIAL
}

\section{INFORMATION TECHNOLOGY AS A SUPPORT FOR SOCIAL PARTICIPATION}

\author{
Ícaro Célio Santos de Carvalho \\ Escola de Administração de Empresas de São Paulo - Fundação Getulio Vargas (EAESP - FGV) \\ Doutorando em Administração de Empresas \\ São Paulo, SP, Brasil \\ Email: icarocelio@hotmail.com \\ Kenyth Alves de Freitas \\ Escola de Administração de Empresas de São Paulo - Fundação Getulio Vargas (EAESP - FGV) \\ Doutorando em Administração de Empresas \\ São Paulo, SP, Brasil \\ Email: kenyth.freitas@gmail.com \\ Camilla Rusciolelli Barbosa \\ Núcleo de Pós-graduação em Administração - Universidade Federal da Bahia (NPGA-UFBA) \\ Doutoranda em Administração \\ Salvador, BA, Brasil \\ Email: camillarb@hotmail.com
}

\section{RESUMO}

A promulgação da Constituição Federal de 1988 institucionalizou canais e mecanismos de participação na Administração Pública, a ruptura com o modelo ditatorial ampliou o horizonte da sociedade, tornando o cidadão um ator social decisório, com poder que transcende $\mathrm{o}$ ato tradicional do voto. O objetivo desse trabalho foi analisar o uso da plataforma online e-SIC no Serviço de Informação ao Cidadão. Assim, foi realizado um diagnóstico acerca do relatório de transparência gerado pela plataforma online. Os resultados apontam que a implantação de sistemas online ainda atinge uma parcela restrita da população, além disso, a implementação da Lei de Acesso à Informação como instrumento normativo de caráter informativo precisa ser aperfeiçoada para desenvolver um perfil ainda mais transparente e democrático de governo, bem como que incentive o cidadão a pesquisar, com menos barreiras à informação das atividades públicas.

Palavras-chave: Inovação. Poder Público. Transparência. Informação. Participação Cidadã.

\section{ABSTRACT}

The Federal Constitution promulgation in 1988 institutionalized channels and mechanisms for participation in Public Administration. The rupture with the dictatorial model makes citizens a social decisionmaker, with power that transcends the traditional act of voting. The aim of this study is to analyze the use of the Citizen Information Service online platform. Thus, a diagnosis was made about the transparency report generated by platform. The results point out that the implementation of online systems still has a significant impact on the population. In addition, the implementation of the Access to Information Law government, as well as to encourage the citizen to search, with less barriers to the information of public activities

Keywords: Innovation. Public Power. Transparency. Information. Citizen Participation.

Data de aprovação: 8 de abril de 2019. 


\section{INTRODUÇÃO}

As iniciativas de consolidação da democracia no Brasil, evidenciadas, principalmente, a partir da promulgação da Constituição Federal de 1988, suscitaram as discussões acerca da participação social nos sistemas de gestão pública. Mais que isso, o texto constitucional foi orientado na busca pela extensão da cidadania à medida que estabeleceu canais e mecanismos participativos legalmente instituídos.

Resultado de um intenso processo de negociação entre grupos sociais diversos, a Constituição emergiu sob um contexto político-econômico em transformação. Além do próprio fim da ditadura, outros fatores sustentaram as iniciativas por maior participação social, entre esses se destacam o sistema multipartidário e o fortalecimento dos movimentos sociais de base (VAZ, 2011).

Tais preceitos motivaram as exigências de novas formas de divulgação das ações governamentais, cuja demanda tem sido suprida com o auxílio dos avanços tecnológicos. Ou seja, ao passo que a tecnologia da informação ( $\mathrm{TI}$ ) avança, mais opções de controle das ações governamentais surgem. Sendo assim, órgãos e entidades públicas são pressionados por maior transparência em suas atividades, promovendo, dessa forma, uma maior interação entre governo e sociedade (ALVES; CARVALHO; BARBOSA, 2014).

Para tanto, as ferramentas tecnológicas de participação social são mecanismos fundamentais de transparência nas ações do governo e como possível combate à corrupção no país. Nesse contexto, o Sistema de Informação ao Cidadão (SIC) se insere como uma importante referência na institucionalização da Lei de Acesso à Informação (LAl), que garante o acesso a qualquer tipo de informação pública, em qualquer esfera e sobre qualquer ação governamental (CONTROLADORIA GERAL DA UNIÃO - CGU, 2012). Sendo assim, é possível observar que a própria democracia se beneficia da participação de diferentes atores nos processos decisórios através desses novos canais. Amplia-se, dessa maneira, a participação societária para além da problematização de situações e da influência nas decisões, fazendo com que a participação seja cada vez mais deliberativa (TEIXEIRA, 1997).

Entretanto, a efetivação dessa lei passa por muitos desafios, principalmente nas escalas regionais e locais (CGU, 2012). Entre esses desafios, podem-se destacar a implementação de canais que atendam a necessidade da população em compreender os novos aspectos relativos à gestão pública, e a promoção da transparência como forma de ampliar a participação popular no fortalecimento da democracia. De modo que, a TI emerge como uma das ferramentas capazes de contribuir para consolidação desse processo (FARIA, 2010).

Deste modo, estudos desta natureza revestem-se de importância por buscar entender as novas formas de administração pública e participação social. Portanto, frente à evidente confluência entre democracia, cidadania e o papel da TI, o objetivo deste trabalho foi realizar um diagnóstico acerca do relatório de transparência gerado pela plataforma online e-SIC e, assim, compreender a conduta desta iniciativa como canal de acesso às informações pela população.

Para isso, inicialmente serão apresentados embasamentos teóricos sobre as Tecnologias da Informação e Comunicação (TICs) no contexto da Administração Pública, seguidos pelos procedimentos metodológicos adotados. Posteriormente, as análises foram realizadas a partir da utilização dos dados disponíveis nos relatórios anuais do sistema, no site da iniciativa de forma pública e livre, seguidas pelas 
considerações finais. Destacando a importância de se discutir a efetividade desses canais alternativos na construção de uma população mais envolvida na gestão pública.

\section{AS TECNOLOGIAS DA INFORMAÇÃO E COMUNICAÇÃO NO CONTEXTO DA ADMINISTRAÇÃO PÚBLICA}

A criação da Administração Pública enquanto ciência teve sua base no final do século XIX, pós Revolução Industrial, diante de um momento de transformações econômicas, políticas e sociais sem precedentes históricos. Assim, em 1887, Woodrow Wilson buscou sintetizar a evolução da Ciência da Administração e a relevância de seu estudo e prática, tratando-a como uma criação e necessidade do século e fruto do estudo de Ciência Política.

Para esse autor, a Administração seria o Governo em ação e tão antiga quanto o próprio, porém, a complexidade oriunda das recentes transformações que o mundo estava experimentando (complexidade do comércio, especulação comercial, dívida pública e etc.) exigiam uma sistematização, justificando a criação de uma Ciência da Administração. Além disso, o governo passou a contar com inúmeros dirigentes e deveria estar atento às opiniões do povo (WILSON, 2005).

Consequentemente, as atribuições do Estado foram ganhando proporções cada vez maiores, seria, portanto, necessário identificar o que deveria ser feito e como deveria ser feito, tendo em vista fortalecer o Governo e torná-lo mais eficiente. Nessa conjuntura, para Wilson (2005, p. 355), "o estudo e a criação administrativa são imperativamente necessários ao bem-estar de nossos governos". Cujo objetivo consistia na busca por princípios sólidos que evitassem os transtornos da experiência empírica.

Segundo Farah (2011), a Administração Pública tem o intuito de abordar as novas configurações do Estado e sua relação com a sociedade, foi desenvolvida para lidar com os desafios que estavam surgindo. De forma mais abrangente, Denhardt (2012) afirma que a fundamentação do estudo da administração pública estava orientada na busca pela extensão da democracia.

Nesse contexto, diante dos recentes avanços, novos paradigmas tecnológicos e transformações sociais e econômicas, a Administração Pública tem sido desafiada a reinventar as suas formas de atuação, cujas novas tecnologias da informação e comunicação revelam-se como aliadas imprescindíveis.

O uso das TICs na administração pública começou na década de 1960. No entanto, essas tecnologias eram empregadas com caráter mais restritivo, em geral, auxiliando atividades rotineiras, como folha de pagamento e contabilidade (LOH, 2014; SANCHEZ; ARAÚJO, 2006). Atualmente, a intensa utilização das TICs por parte dos governos tem fortalecido a estruturação de programas no meio eletrônico, que surgem com o objetivo de fomentar a modernização na administração pública (BARBOSA, 2013).

Tal modernização contribui para o aumento da eficiência dos processos internos do governo, bem como melhoria da qualidade dos serviços, redução de custos, aumento da produtividade dos servidores e, principalmente, a transparência e controle social (BARBOSA, 2013). O desenvolvimento das TICs tem reflexo no funcionamento dos governos e nas dinâmicas sociais, econômicas e políticas da sociedade (FREIRE; STABILE, 2013).

Os avanços conquistados com relação aos mecanismos e canais de participação cidadã institucionalizados a partir da promulgação da Constituição Federal de 1988 buscaram estreitar a relação 
entre o governo e sociedade, com muitos instrumentos facilitadores nessa relação, bem como as ouvidorias, as redes sociais, as plataformas digitais, entre outros. Estes sistemas de informação interligados tem um objetivo em comum de auxiliar o cidadão e demais organizações desde simples consultas à resolução de problemas (O'BRIEN, 2011; LAUDON; LAUDON, 2011).

Segundo Faria (2010), as oportunidades criadas por tais canais de comunicação funcionam como uma "sinergia positiva" entre o governo e a sociedade civil, considerando os novos espaços participativos, reconhecendo que embora importante para assegurar a dinâmica inclusiva, não é suficiente. Segundo Rover e Mezzaroba (2011), alguns estudos estão cunhando o termo "ciberespaço" como um espaço democrático criado pelas novas tecnologias que proporciona a liberdade de expressão em espaços virtuais.

De acordo com estes autores, isso abre espaço para uma nova forma de cooperação e comunicação, a chamada "ciberdemocracia". Considera-se, portanto, que os canais eletrônicos do governo abrem novos meios de organização de informação e conhecimento que permite que atos burocráticos desapareçam e facilitem o acesso às informações e acesso às ações governamentais (ROVER; MEZZAROBA, 2011).

Atualmente o Estado tem investido em inovações que estreitam a relação entre os cidadãos e governo, destaca-se o SIC (Serviço de Informação ao Cidadão) como um importante instrumento de interação entre a administração pública e a sociedade civil. Para Bohnman (2009), a publicidade de informações do setor público é base do aperfeiçoamento das decisões de governo, já que as mesmas estão abertas a um leque maior de opiniões alternativas que podem conduzir a uma melhor escolha. Isso resulta por motivar os cidadãos a cooperarem com a gestão pública, mesmo em situações onde há divergência de opiniões.

Cabe destacar que há diferentes formas de enxergar tais instrumentos de aperfeiçoamento da democracia e de participação cidadã. Akutsu (2002) aponta a divisão em dois grupos: os utópicos e os "pessimistas" ou anti-utópicos. Os utópicos acreditam na capacidade de ampliação da informação e consciência política dos cidadãos diante do avanço das novas tecnologias; por outro lado, os anti-utópicos entendem como uma maneira dos governos aumentarem seu controle sobre a sociedade, uma vez que, embora haja um maior fluxo de informações, a divulgação ficará restrita ao interesse dos grandes grupos econômicos e detentores do poder político.

De qualquer modo, são inegáveis as transformações causadas pelo crescimento das tecnologias de informação e comunicação no cotidiano social e político, no qual podemos identificar elementos que convergem tanto com as crenças dos utópicos, quanto dos pessimistas.

Indubitavelmente o acesso à informação foi facilitado nos últimos anos, e o despertar da consciência política já pode ser visto através da popularização de assuntos relacionados à política nos mais diversos meios, das tentativas de pressionar os parlamentares usando as redes sociais e os canais de comunicação disponíveis, da influência da internet nos resultados das eleições, dentre muitos outros exemplos. Entretanto, os anti-utópicos parecem ter razão quando apontam interferência ainda praticada pelos detentores do poder político e econômico na divulgação das informações.

Essas constatações levam a um meio termo, onde é possível enxergar as duas perspectivas como componentes da trajetória do exercício de democracia e cidadania no Brasil. Segundo Akutsu (2002): "democracia pressupõe cidadania ativa e a cidadania plena só pode ser exercida numa democracia".

Não por acaso, Souza (2000) assevera que "que existe uma íntima imbricação entre ideias, práticas e instituições sociais", de modo que a modernização no Brasil deve ser pensada considerando esse preceito. 
Ou seja, para pensar em ideias e sugestões é preciso pensar antes nas práticas que permitirão a sua execução, o que envolve tradições culturais e comportamentais, somado às instituições que atuam em diferentes conjunturas.

Portanto, considera-se que a informação seja um importante aliado do cidadão e, dessa forma, a ausência de conhecimento sobre tais elementos pode retardar os avanços democráticos alcançados pela sociedade. A participação cidadã é um direito conquistado após anos de ditadura, previsto na Constituição Federal de 1988 em seu artigo $5^{\circ}$, que dispõe da garantia do acesso às informações públicas e da transparência, eixos essenciais de um governo aberto à participação social, que visa unir democracia representativa e participativa.

Assim, as novas tecnologias podem promover maior ligação entre as escalas espaciais, principalmente a esfera Local e a Nacional. Além disso, as TICs podem ser utilizadas para fortalecer a educação cívica por meio da garantia de acesso igualitário à informação e do envolvimento dos indivíduos em redes que possibilitem uma participação cívica mais efetiva. Dessa maneira, a participação direta exerce também uma função educativa, diante do envolvimento da sociedade na vida política da nação. Pensando nisso, diversos países têm investido no desenvolvimento das TICs para a disseminação e ampliação do espaço virtual (PATEMAN, 1992; BARBER, 1984).

Diante do exposto, ressalta-se a importância em disseminar os resultados dos esforços do governo na promoção da participação social. Faz-se necessário analisar o impacto dessa lei no cotidiano dos cidadãos brasileiros e observar quais os próximos passos a serem dados para a consolidação da participação no Brasil.

\section{A participação cidadã, a Lei de Acesso à Informação e o Controle Social no contexto do Sistema de Informação ao Cidadão}

A participação cidadã engloba as várias formas de participação, concebidas ou exercitadas por alguns regimes políticos, a dicotomia entre a participação indireta, no sentido mais amplo, e direto, no sentido estrito (TEIXEIRA, 1997). Segundo Rossetto et al. (2005), por participação política significa dizer que a comunidade detém poder deliberativo, autonomia em relação às forças políticas e desenvolve capacidades para a participação. Para Vaz (2011), o fenômeno da participação política tem crescido e diversificado no Brasil, principalmente em nível municipal/local. Nesse contexto, a transparência possibilita que seja assegurada a integridade da prestação do serviço público, ou pelo menos o seu acompanhamento.

Ao refletir acerca da legitimidade das políticas via eleições, podem-se observar alguns limites como a compra de votos e influência da cultura política local, considerando as experiências na América Latina que demonstram casos frequentes de corrupção. Portanto, há a necessidade de ampliação da participação política da sociedade a fim de fortalecer a democracia para além do escrutínio (ALVES; CARVALHO; BARBOSA, 2014; ESTHER, 2009). Pois como afirma Bobbio (1994), a democracia é uma forma de governo cujo poder está relativamente na mão de todos, muito embora a democracia representativa exercida nos moldes atuais "acaba por ser praticada pela maioria dos indivíduos somente nas eleições, após elas, tornam a ser subalternos" (BOBBIO, 1994, p. 33).

$\mathrm{Na}$ tentativa de contrariar esta conjuntura, o controle das políticas públicas aparece como caráter central em diversos movimentos sociais latino-americanos. A ideia é criar mecanismos que obriguem os 
governantes a cumprir com o prometido nas campanhas eleitorais. Dessa forma, esses movimentos buscam através da "accountability governamental", o atendimento do interesse dos cidadãos (GASPARDO; FERREIRA, 2017; FIABANE, 2011).

A participação cívica necessita, portanto, de canais e mecanismos institucionais de participação. No Brasil a Lei de Acesso a Informação ( $N^{\circ}$ 12.527/11) é responsável por garantir que todo e qualquer cidadão tenha o direito de acesso às informações de toda entidade pública, pois essas instituições têm o dever de informar, de forma entendível, sobre o dinheiro que é utilizado em suas ações e prestar contas dos seus atos. Quaisquer informações produzidas ou custodiadas pelo poder público e não classificadas como sigilosas são consideradas públicas e, consequentemente, devem estar acessíveis a todos os indivíduos.

A LAI foi recebida como um mecanismo capaz de possibilitar avanços no exercício dos direitos cívicos, ampliando os meios de acompanhamento e fiscalização a partir da regulamentação dos preceitos constitucionais de publicidade, tratando o sigilo como uma exceção à regra. Com isso, objetiva-se ganhos de qualidade na prestação do serviço público, mediante o auxílio da sociedade. Especificamente, essa lei definiu procedimentos e regras que dizem respeito aos prazos para atendimento das solicitações, instâncias de recursos, obrigações de divulgação e sanções para os agentes públicos que descumprirem a legislação (SEABRA, et. al. 2013).

De acordo com Bucci (2013, p.117), qualquer decisão estatal "implica escolhas e, portanto, a existência de interesses contemplados e outros preteridos". Sendo assim, inovações no acesso à informação contribuem para maior democratização dos processos de desenvolvimento de políticas públicas, incluindo a participação de um maior número de estratos sociais (GASPARDO; FERREIRA, 2017).

Nesse ponto, Serafim (2008) concorda que, no que tange o exercício do controle social, é necessário que os cidadãos tenham acesso às informações acerca das ações da gestão pública, participando por meio dos canais de debate, intervindo nas fases de construção e implementação de políticas públicas. Dessa forma, com a sociedade inserida e consultada, maior a probabilidade de que possíveis irregularidades sejam punidas.

Para esse autor, existem três componentes principais para a compreensão do controle social, sendo eles: (i) o acesso à informação; (ii) canais de interlocução e partilha de poder com o Estado, considerando também a participação nas políticas públicas; (iii) instrumentos de punição eficazes à irregularidade na gestão pública (SERAFIM, 2008). Desse modo, novas tecnologias abrem espaço para maior participação social.

Contudo, conforme observam Ribeiro et al (2011), é inegável a capacidade das instituições públicas em produzirem uma grande quantidade de informações, a questão está justamente na maneira como essas informações são disponibilizadas e disseminadas, sejam internamente no próprio governo ou no acesso aos cidadãos. A gestão destas informações deve, fundamentalmente, ser feita de forma adequada de modo a possibilitar a geração de conhecimento, bem como acumulação e aprendizado com as experiências, a fim de que sejam úteis às tomadas de decisão.

Seabra et al (2012) salientam a importância de avaliar os diferentes contextos para implementação da LAI e seus desdobramentos no Brasil, entretanto, sugerem um processo que consiste em: "- organizar participação; criar estrutura e canais de acesso; estabelecer rotinas/fluxos internos de informações; e institucionalizar a cultura de acesso à informação".

Um exemplo disso tem sido o SIC que possui responsabilidade de atender e orientar os cidadãos acerca do acesso a informações da administração pública. Além disso, tem o objetivo de informar sobre o 
andamento das tramitações de documentos, e realizar o protocolo de documentos e requerimentos que possibilitem este acesso, podendo receber pedidos de informação por meio presencial e eletrônico, dentro da plataforma do Sistema Eletrônico de Informação ao Cidadão (e-SIC).

\section{METODOLOGIA}

Os aspectos metodológicos deste trabalho priorizaram técnicas e estratégias da abordagem qualitativa. Muito embora os números referentes às respostas aos pedidos de informação pelo sistema e-SIC sejam o pilar da pesquisa, sua base consiste na interpretação dos fenômenos e a atribuição de significados (FLICK, 2009).

Assim, esta pesquisa possui caráter aplicado, já que tem como finalidade solucionar problemas práticos e operacionais, podendo ser classificado como exploratória, descritiva e explicativa por ressaltar a importância da disseminação dos documentos relativos à transparência no setor público, aspecto esse garantido desde a Constituição Federal brasileira (1988).

Como técnica, foram utilizados documentos em forma de texto, legislação e dados de arquivos eletrônicos para o alcance dos objetivos propostos, uma vez que servem como forma de contextualização da informação (FLICK, 2009). Recorrendo à análise documental buscou-se entender e investigar os resultados gerados a partir dos relatórios de participação cívica na gestão pública, através da plataforma online de acesso à informação ao cidadão. Por ter "como principal finalidade a formulação de problemas mais precisos ou hipóteses pesquisáveis para estudos posteriores" (GIL,1999, p. 43), a presente pesquisa possui natureza exploratória.

Quanto à coleta dos dados secundários, deu-se a partir da pesquisa bibliográfica, documental e exploratória, desenvolvida com base em material especializado constituído, principalmente de livros e artigos científicos, e valendo-se de materiais que não recebem ainda um tratamento analítico, ou que ainda podem ser reelaborados de acordo com os objetos da pesquisa (GIL, 2002). Os dados utilizados foram gerados pela plataforma do Sistema de Informação do cidadão, o e-SIC, no período de maio de 2012 a abril de 2017, o que possibilitou acompanhar os cinco anos de implantação dessa inciativa.

A trajetória da plataforma de acesso à informação começou com a sanção da Lei Federal $n^{\circ} 12.527$ em 18 de novembro de 2011, cujo propósito era regulamentar o que já estava previsto no texto constitucional de 1988, o direito de acesso dos cidadãos às informações públicas, devendo ser aplicada aos três Poderes de todos os entes federativos.

Nessa circunstância, a operacionalização e gerenciamento das solicitações realizadas a partir da vigência da LAI, no âmbito federal, foram possibilitados por meio da criação do e-SIC (Sistema Eletrônico do Serviço de Informações ao Cidadão), oportunizado pela Controladoria-Geral da União (CGU). Entre outras coisas, este sistema permite a solicitação de informação e documentos que dizem respeito à gestão pública. No Poder Executivo Federal seu uso é obrigatório, e mesmo as solicitações feitas por meios físicos precisam ser registradas no e-SIC (CGU, 2016). Mas sua funcionalidade não se restringe apenas à solicitação de informação da gestão, é possível ainda acompanhar o cumprimento do prazo de respostas, consultar respostas, impetrar recursos, e registrar reclamações, por exemplo, como esclarece a CGU (2016). Para 
execução desta pesquisa, contamos com a função que permite obter as estatísticas de atendimentos no sistema.

Os relatórios estatísticos gerados estão disponíveis para acesso público de qualquer indivíduo e tratam sobre os seguintes assuntos; pedidos, recursos e reclamações. No âmbito deste trabalho, utilizaramse especificamente os relatórios de pedidos de acesso à informação e solicitantes, cujos dados consultados referem-se aos pedidos relativos a toda Administração Pública Federal no período observado, conforme exposto na análise dos resultados e discussão a seguir.

\section{ANÁLISE DOS RESULTADOS E DISCUSSÃO}

A plataforma e-SIC disponibiliza dados de forma livre e objetiva sobre os tipos de solicitações, perfil dos usuários, recursos e reclamações. Sendo assim, permite-se estabelecer o desempenho da plataforma perante as consultas públicas realizadas. Por meio desta ferramenta foi possível verificar como os cidadãos utilizam esse novo canal de comunicação. Com relação ao número de acessos identificou-se uma tendência crescente, passando de 92.894 no ano de implantação para 108.051 no último ano completo do sistema em execução, de maio de 2015 a junho de 2016.

Uma das principais características referentes aos pedidos de acesso realizados pelos cidadãos consiste no fato da internet ser o meio mais utilizado, no primeiro ano aproximadamente $95 \%$ das solicitações por informações foram feitas através desse meio, no quinto ano foram 98,45\%. Existem outras formas de obter respostas do sistema, como a consulta pessoal e correspondência física com custo, embora bem menos utilizadas e com a participação em queda. Mesmo assim é importante que esses meios ainda existam, visto que nem toda população possui acesso à internet, como pessoas de baixa renda ou idosos. Possibilitar o acesso dessa parcela da população torna o processo mais democrático (SERAFIM, 2008). Adicionalmente, ressalta-se a importância de dinamizar o espaço de interação, ao torná-lo mais acessível e mais fácil para os usuários (GASPARDO; FERREIRA, 2017).

No que se refere ao desempenho do sistema em fornecer respostas aos pedidos, de acordo com o relatório e-SIC (2013/2014), o tempo médio de resposta foi de 11,73 dias no primeiro ano de operação e de 13,31 dias no quinto ano. Como a CGU (2012) prevê que "todos os órgãos públicos deverão fornecer os dados solicitados no prazo de 20 dias, prorrogáveis por mais 10 , sem que haja necessidade de o requerente justificar o pedido", observa-se que o tempo médio de resposta da plataforma tem sido inferior ao estipulado pela LAI (BRASIL, 2014).

Ainda assim, muito embora o tempo médio de resposta tenha se mantido inferior ao estabelecido na lei, preocupa o aumento dos pedidos em tramitação fora do prazo. Nos primeiros anos, esse tipo de resposta não chegava a $1 \%$ do número total de pedidos. No entanto, no último ano ocorreu um salto desse tipo de resposta, para $5,76 \%$. Tal queda de desempenho pode ser resultado das restrições fiscais dos últimos dois anos, que podem ter restringido os recursos para essa iniciativa (MOURA; RIBEIRO, 2017). Além disso, soma-se o aumento das solicitações e a mudança do teor das consultas, como pode ser visto no Gráfico 1. 
Gráfico 1 - Principais temas solicitados no e-SIC no $1^{\circ}$ ano $(2012 / 2013)$ e no $5^{\circ}$ ano $(2016 / 2017)$ de operação

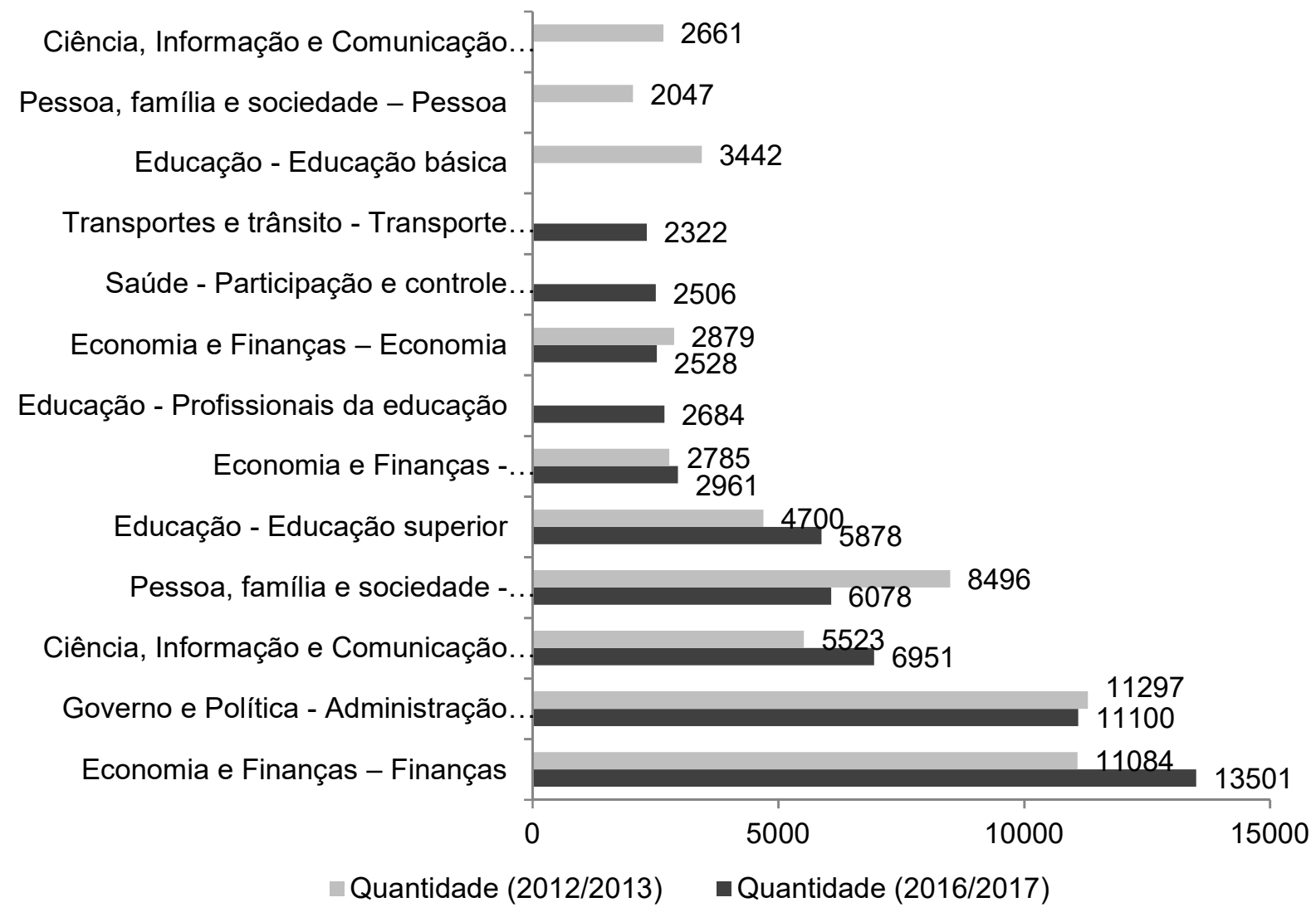

Fonte: Elaborado pelos autores.

No primeiro ano de implantação os temas mais recorrentes eram "Governo e Política - Administração pública" (11,95\%), "Economia e Finanças - Finanças" (11,72\%) e "Pessoa, família e sociedade - Previdência social" (8,99\%), enquanto no quinto ano foi de "Economia e Finanças - Finanças" (13,04\%), "Governo e Política - Administração pública" (10,72\%) e "Ciência, Informação e Comunicação - Informação - Gestão, preservação e acesso" (6,71\%). Além de questões ligadas ao transporte/trânsito, saúde e educação, que em 2012/2013 nem figuraram entre os temas solicitados. Essas novas temáticas podem ter demandado novos conhecimentos da equipe do SIC, o que resultou em respostas mais lentas e, consequentemente, no aumento dos atrasos.

O sistema e-SIC traça o perfil do solicitante, que inclui não somente pessoa física, como empresas, instituições de ensino, ONG's, partidos políticos, entre outros. Segundo o sistema, não houve variações significativas no perfil dos usuários. As solicitações por informações tiveram sua maioria feita por pessoa física com $95,54 \%$, seguido por apenas $4,46 \%$ das solicitações feitas por pessoa jurídica.

Do total de solicitações, a maior concentração é do estado de São Paulo com 24,92\%, seguido por Rio de Janeiro com 13,04\% e Minas Gerais com 9,95\%. Dado que reflete a participação total da população por estados (IBGE, 2017), bem como demonstra a maior difusão do sistema entre os estados da região Sudeste. Embora consideremos o contingente populacional, nota-se que a participação deve ser difundida de forma equitativa pelo país, o que poderia ser considerado um ponto positivo no alcance a democratização das 
informações (SERAFIM, 2008). No entanto, o que mais chama atenção no perfil dos solicitantes é o nível de escolaridade (Gráfico 2).

\section{Gráfico 2 - Nível de escolaridade do solicitante do sistema e-SIC}

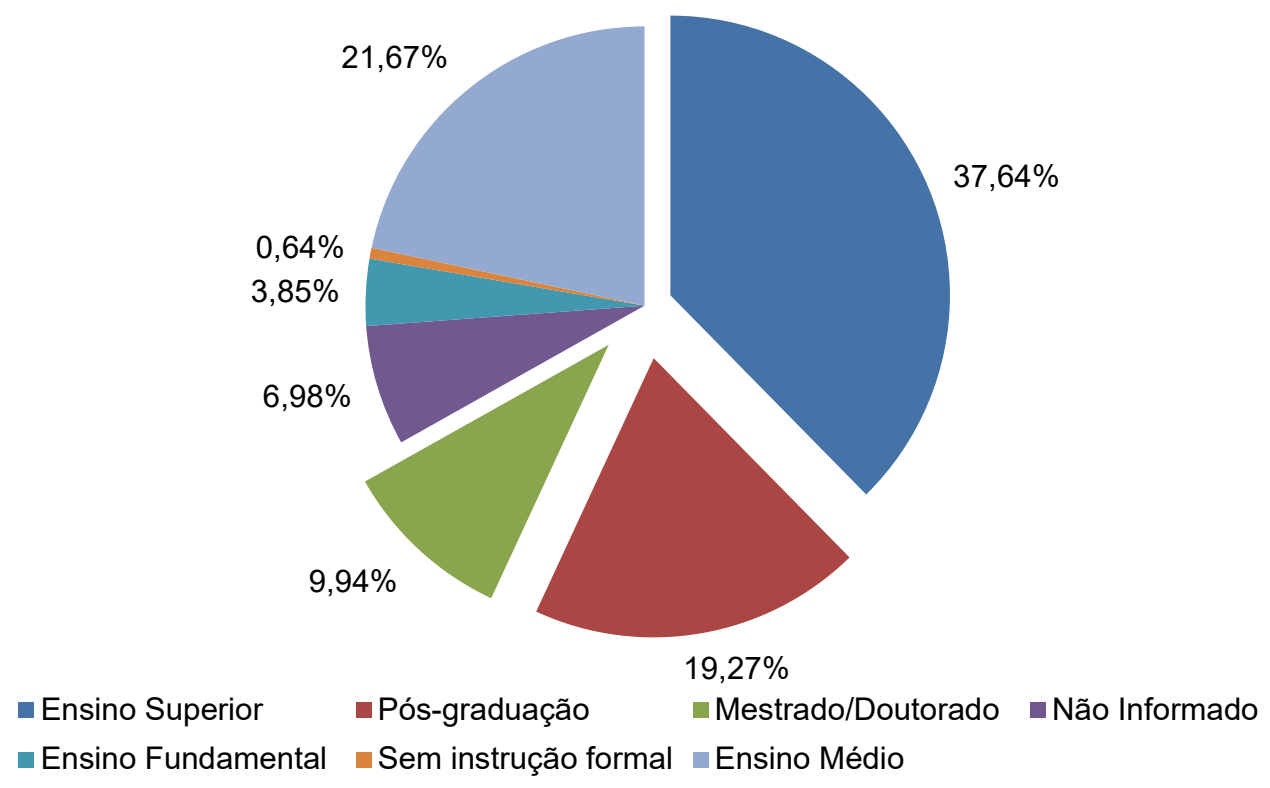

Fonte: Elaborado pelos autores.

Elemento fundamental para descrever o perfil dos solicitantes que acessam o SIC, o nível de escolaridade trata-se de uma variável capaz de influenciar na busca por informações. Percebe-se nesse caso que o maior índice de solicitação é feito pelo cidadão que possui ensino superior com $37,64 \%$, seguido pelas categorias "ensino médio" (21,67\%), "pós-graduação" (19,27\%), "mestrado/doutorado" (9,94\%), "ensino fundamental" (3,85\%), e, em menor parcela, "sem instrução formal" (0,64\%). A distribuição escolar dos usuários do sistema mostra-se muito distante da realidade da população brasileira (IBGE, 2017).

De acordo com estimativas do Instituto Brasileiro de Geografia e Estatística - IBGE (2017), aproximadamente $8 \%$ da população possuía curso superior em 2010 no Brasil. Mesmo reconhecendo o aumento das matrículas no ensino superior nos últimos anos, a cifra não chega a ser compatível com os $66,85 \%$ de usuários do sistema que possuem esse nível de escolaridade, sinalizando uma assimetria entre o perfil populacional e o de quem acessa a plataforma. Esta evidência gera um alerta para um sistema cuja principal função é oferecer acesso à informação para toda uma população (CGU, 2012), sinalizando que grande parte dos indivíduos, sobretudo os de menor nível de escolaridade, permanece à margem das esferas de participação e cidadania.

Por conseguinte, o acesso reduzido de pessoas com níveis mais baixos de escolaridade às informações do governo resulta em menor participação nas decisões governamentais (GASPARDO; FERREIRA, 2017; BUCCI, 2013). Para elucidar essa questão, segundo pesquisa realizada por Abreu e Pinho (2014), diversificar as formas de acesso às informações se mostrou uma forma democrática de participação nos processos de decisão, embora apostem no potencial latente das TICs para integrar pessoas de diferentes estratos sociais. 
As barreiras de acesso às informações governamentais ainda são visíveis e mantém a população com menores níveis de escolaridade afastada do processo, como identificado nesta pesquisa com dados da plataforma e-SIC. Por outro lado, uma pesquisa divulgada pelo eMarketer (2016) aponta que o Brasil é o país que mais usa redes sociais na América Latina, com previsão de alcançar 105,2 milhões de usuários em 2020. Observa-se com isso a necessidade de aliar os avanços na difusão das TICs ao interesse por assuntos relacionados à transparência e responsabilidade na Administração Pública.

Consequentemente, é imperativo ampliar os investimentos em mudanças estruturais da educação no Brasil, além de combater a exclusão digital, tratada como dimensão importante na implementação de um governo mais inclusivo e participativo. Busca-se dessa forma, unir os avanços promovidos pela tecnologia aos mecanismos de acompanhamento e participação que aproxime Estado e sociedade.

\section{CONSIDERAÇÕES FINAIS}

Os avanços de modernização do serviço público, iniciados timidamente na década de 90 com a reforma gerencial vivenciada no Brasil, e impulsionados pelo texto constitucional de 88 , viabilizaram significativas melhorias para o exercício do controle social na gestão pública. Neste estudo, especificamente, verificou-se a importância da inovação, tanto voltada para a forma como é conduzido o processo burocrático de acesso, como também para o uso da tecnologia na Administração Pública.

Contudo, a modernização administrativa esbarra em questões estruturais, tendo em vista que além de simplificar rotinas, possibilitar acesso e ampliar a disponibilidade e informações, é preciso viabilizar e estimular a participação dos mais diversos estratos sociais da população, bem como promover um acesso mais igualitário à educação formal. A análise do perfil dos usuários do sistema e-SIC apontou que a maioria dos solicitantes possuía nível superior, uma assimetria que contraria o perfil educacional da população brasileira composta minoritariamente (apenas $8 \%$ em 2010) por indivíduos com esse atributo.

A importância da Lei de Acesso à Informação como instrumento normativo de caráter informativo ao cidadão cria novas possibilidades de busca por informações na administração pública, e assim, pode-se desenvolver um perfil mais transparente no governo, essencial a qualquer bem ou serviço público. No entanto, existe um risco de excluir uma parcela da população que não possui acesso aos serviços educacionais. Conforme verificado na participação majoritária de pessoas com curso superior utilizando essa plataforma, fato que não representa a população geral.

Em que pese à baixa procura pela população de menor escolaridade à plataforma e-SIC, o Brasil vem se destacando no cenário mundial com um dos maiores números de usuários das redes sociais, cujos efeitos já podem ser vistos na política e sua influência no processo eleitoral. Consequentemente, destaca-se o papel relevante e atual de entender como a tecnologia tem servido tanto para influenciar o cenário político, como também para ser um meio de interação entre governo e sociedade, estreitando essa relação e possivelmente contribuindo para uma maior participação social.

Com relação ao comportamento da sociedade frente ao novo horizonte social, os resultados indicam que mesmo sendo uma plataforma recente houve um alto nível de procura por informações e pode sinalizar interesse social em participar e transformar a Administração Pública em um espaço menos corrupto e mais 
transparente. A caracterização dos solicitantes mostrou as primeiras camadas sociais atingidas pelos efeitos da Lei de Acesso à Informação e a utilização dos recursos tecnológicos aplicados no governo.

Cabe ressaltar que a efetivação e disseminação dos instrumentos previstos pela LAl podem promover diversos avanços sociais, a partir da disponibilidade do acesso a informação dos processos, dos resultados ou gastos de qualquer que seja o departamento de qualquer um dos poderes. O governo precisa, portanto, aprimorar cada vez mais a aplicação de novas práticas que agreguem a sociedade, sendo mais transparente e tornando-se mais eficiente em seus resultados, para isso, salienta-se a importância da inovação tecnológica na Gestão Pública no fomento de melhores práticas.

Embora a realidade brasileira conviva ainda com instituições patrimonialistas, clientelistas, autoritárias e corruptas, é preciso desenvolver, aprimorar e aplicar os instrumentos capazes de reverter essa trajetória. Desse modo, busca-se respaldo em um dos princípios constitucionais, a publicidade institucional, concebido com o intuito de proporcionar a transparência e o controle da Administração Pública pela população, atribuindo ao povo o poder/dever de fiscalização.

Conclui-se que a relevância desse princípio depende da conscientização da sociedade quanto ao seu necessário exercício de cidadania, que deve estar combinado à mobilização para tornar possível a consolidação da democracia, um imperativo no atual cenário político do país. Nesse sentido, o advento e a popularização das tecnologias da informação parecem indicar uma oportunidade de ampliação dos serviços prestados pelo Estado, bem como do acompanhamento das decisões governamentais e destinação dos recursos públicos por parte dos cidadãos.

\section{REFERÊNCIAS}

AKUTSU, Luiz. Sociedade da Informação, Accontability e Democracia Delegativa. Editora Baraúna: 2002.

ALBUQUERQUE, M. Participação Cidadã nas Políticas Públicas. In: HERMANNS, K. (Ed.). Participação Cidadã - Novos Conceitos e Metodologias. 1a. ed. Ceará - Fortaleza: Expressão Gráfica e Editora, 2004.

ALVES, A.; BARBOSA, C.; CARVALHO, I. As Múltiplas Formas de Controle da Gestão Pública a Partir da Constituição Federal de 1988. In: XVII Semana do Administrador do Sudoeste da Bahia - O Administrador da contemporaneidade: desafios e perspectivas, 2014.

BARBER, B. Strong Democracy. Los Angeles: University of California Press, 1984.

BARBOSA, A. Pesquisa sobre o uso das tecnologias da informação e comunicação no setor público brasileiro: TIC Governo Eletrônico, 2014.

BOBBIO, Norberto -Liberalismo e Democracia. SP. Brasiliense.1994.

BOHMAN, J. O que é a deliberação pública? Uma abordagem dialógica. In: MARQUES, Ângela C. S. (Org.). A deliberação pública e suas dimensões sociais políticas e comunicativas: textos fundamentais. Belo Horizonte: Autêntica, 2009. p. 3184.

BRASIL. Constituição (1988). Constituição da República Federativa do Brasil. Brasília, DF: Senado, 1988.

BRASIL. Lei de Acesso à Informação (LAI). Disponível em: http://www.acessoainformacao.gov.br/sistema/site/index.html?ReturnUrl=\%2fsistema\%2f>, acessado em 01 de fevereiro de 2018.

BRASIL. Relatório anual do sistema e-SIC, disponível no endereço eletrônico: <http://www.acessoainformacao.gov.br/sistema/Relatorios/Anual/RelatorioAnualPedidos.aspx>.

BRASIL. Serviço de Informações ao Cidadão (SIC). Disponível em: <http://www.mc.gov.br/acessoainformacao/servicode-informacoes-ao-cidadao-sic> Acessado em 01 de fevereiro de 2018.

BUCCI, M. P. D. Fundamentos para uma teoria jurídica das políticas públicas. São Paulo: Saraiva, 2013.

CASTRO, Domingos P. Auditoria e controle interno na administração pública. São Paulo: Atlas, 2008.

CONTROLADORIA GERAL DA UNIÃO (CGU). Lei de Acesso à Informação entra em vigor hoje. Brasília, 2012. Disponível em: <http://www.cgu.gov.br/imprensa/Noticias/2012/noticia06612.asp>, Acesso em 06 de fevereiro de 2018. 
CONTROLADORIA GERAL DA UNIÃO (CGU). Manual do SIC. Brasília, outubro de 2016. Disponível em: <https://esic.cgu.gov.br/sistema/site/dicas_pedido.html>. Acesso em 19 de março de 2018.

DENHARDT. Teorias de Administração Pública. São Paulo: Cengage Learning, 2012 (cap.7 - Administração Pública e o Novo Serviço Público).

EMARKETER. Social Network Users in Latin America, by Coutry, 2015-2020. June 2016. Disponível em: <https://www.emarketer.com/Chart/Social-Network-Users-Latin-America-by-Country-2015-2020/199801>. Acesso em 05 de março de 2018.

ESTHER, R. Accountability, Democracia e Cidadania Organizada: uma análise do

FARAH, Marta. Administração Pública e Política Pública. Revista de Administração Pública (Impresso), v. 45, p. 813-836, 2011.

FARIA, C. Estado e Organizações da Sociedade Civil no Brasil contemporâneo: construindo uma sinergia positiva? Revista Sociologia Política, 2010.

FIABANE, Danielle F. Controle social: um novo frame nos movimentos sociais. Dissertação (mestrado em administração pública e governo) - Escola de Administração de Empresas, Fundação Getulio Vargas, São Paulo, 2011. Disponível em: <http://bibliotecadigital.fgv.br/dspace/bitstream/handle/10438/8233/Controle\%20social_um\%20novo\%20frame\%20nos\% 20movimentos\%20sociais\%20(2).pdf?sequence=5>. Acesso em 6 jan. 2018.

FLICK, Uwe. Introdução à pesquisa qualitativa. 3. ed. Porto Alegre, RS: Artmed: Bookman, 2009.

FREIRE, F.; STABILE, M. As novas tecnologias e a participação eletrônica: entre promessas e desafios, 2013.

GASPARDO, M.; FERREIRA, M. Institutional innovation and participatory democracy: mapping on legislation regarding the implementation of Programs of Goals in Brazilian cities. Revista de Administração Pública, v. 51, n. 1, p. 129-146, 2017.

GIL, A. Como elaborar projetos de pesquisa. 4. ed. - São Paulo: Atlas, 2002.

HABERMAS, J. Between Facts and Norms. London: Polity, 1996.

LAUDON, J. P.; LAUDON, K. C. Sistemas de informação gerenciais. 9. ed. Pearson: São Paulo, 2011.

LOH, S. 31 tipos de sistemas de informação. Porto Alegre, 2014.

O'BRIEN, J. A. Sistemas de informação e as decisões gerenciais na era da internet. 3. ed. Saraiva: São Paulo, 2011.

PATEMAN, C. Participação e Teoria Democrática. Rio de Janeiro: Paz e Terra, 1992.

PUTNAM, R. Comunidade e democracia: a experiência da Itália moderna. Rio de Janeiro: Fundação Getúlio Vargas, 1996.

RIBEIRO, Clarice Pereira de Paiva et al . Difusão da informação na administração pública. Transinformação, Campinas , v. 23, n. 2, p. 159-171, Aug. 2011. Disponível em <http://www.scielo.br/scielo.php?script=sci_arttext\&pid=S0103$37862011000200006 \&$ Ing=en\&nrm=iso>. Acesso em 15 de janeiro de 2018.

ROSSETTO, A.; ORTH, D.; ROSSETTO, C. Uma proposta de Balanced Scorecard para o desenvolvimento local, 2005.

ROVER, A.; MEZZAROBA, O. NOVAS TECNOLOGIAS: o governo eletrônico na perspectiva da governança. In: Empresa, sustentabilidade e funcionalização do Direto. São Paulo: Editora Revista dos Tribunais, 2011.

SANCHEZ, O. A.; ARAÚJO, M. Avaliação dos mecanismos de controle da corrupção e de valorização da cidadania no estado de São Paulo. São Paulo: Cedec, 2006.

SEABRA, Sérgio Nogueira; CAPANEMA, Renato de Oliveira; FIGUEIREDO, Renata Alves. Lei de Acesso à Informação: uma análise dos fatores de sucesso da experiência do poder executivo federal. Revista de Administração Municipal IBAM. Ano 58. № 282. Rio de Janeiro, 2013.

SERAFIM, L. Controle Social: Que caminhos? In: Instituto Pólis, 2008.

SOUZA, Jessé. A modernização seletiva: uma reinterpretação do dilema brasileiro. Brasília, Editora da Universidade de Brasília, 2000.

TEIXEIRA, E. As dimensões da Participação cidadã, 1997.

VAZ, A. Participação política, efeitos e resultados em políticas públicas: notas crítico-analíticas. Opinião Pública, v. 17 , n. 1, p. 163-205, 2011.

WILSON, Woodrow. O Estudo da Administração. Revista do Serviço Público. Brasília 56 (3): 349-366 Jul/Set 2005. (trad. de The Study of Administration in Political Science Quarterly em 1887. Tradução originalmente publicada na RSP em maio de 1946 (Ano 9, v. 2, n. 2)). 